\title{
Glucose- and insulin-induced phosphorylation of the insulin receptor and its primary substrates IRS- 1 and IRS-2 in rat pancreatic islets
}

\author{
L.A. Velloso ${ }^{\mathrm{a}, *}$, E.M. Carneiro ${ }^{\mathrm{b}}$, S.C. Crepaldi ${ }^{\mathrm{b}}$, A.C. Boschero ${ }^{\mathrm{c}}$, M.J.A. Saad ${ }^{\mathrm{a}}$ \\ ${ }^{a}$ Laboratory of Cellular and Molecular Biology, Department of Internat Medicine. State University of Campinas (UNICAMP), Campinas SP, Brazil \\ 'Department of Physical Education, State University of São Paulo (UNESP). São Paulo SP, Brazil \\ "Department of Physiology and Biophysics, Siate Lniversity of Campinas (UNICAMP). Campinas SP. Brazil
}

Received 11 September 1995: revised version received 11 November 1995

\begin{abstract}
The presence of tyrosine-phosphorylated proteins was studied in cultured rat pancreatic islets. Immunoblotting performed with total extracts of islets cultured in the presence of 1.8 or $5.6 \mathrm{mM}$ glucose revealed at least three distinct tyrosinephosphorylated bands ( $25 \mathrm{kDa}, 95 \mathrm{kDa}$ and $165-185 \mathrm{kDa})$. After $12 \mathrm{~h}$ incubation in medium containing $1.8 \mathrm{mM}$ glucose, a pulse exposition to 11 or $22 \mathrm{mM}$ glucose or to $10^{-7} \mathrm{M}$ insulin led to a substantial increase in the phosphorylation of all three bands, with no appearance of novel bands. Immunoprecipitation with specific antibodies demonstrated that the signal detected at $95 \mathrm{kDa}$ corresponds to the $\beta$ subunit of the insulin receptor (IR) while the band at $165-185 \mathrm{kDa}$ corresponds to the early substrates of the insulin receptor, IRS-1 and IRS-2. Immunoprecipitation with IRS-1 or IRS-2 antisera detected their association with the lipid metabolizing enzyme phosphatidylinositol 3-kinase (PI 3-kinase). Thus, this is the first demonstration that elements involved in the insulinsignalling pathway of traditional target tissues are also present in pancreatic islets and are potentially involved in auto- and paracrine-signalling in this organ.
\end{abstract}

Key words: Insulin; Insulin receptor: Insulin receptor substrate $1 / 2$; Islet of Langerhans

\section{Introduction}

Protein tyrosine phosphorylation is an important mechanism of intracellular signalling. Insulin action in target tissues is initiated by binding of the ligand to its receptor (IR). promoting the autophosphorylation of its $\beta$ subunit and subsequently triggering a cascade of intracellular signalling [1]. Two early substrates of the activated IR are the $165,000-185,000 M_{r}$ IRS-1 and IRS-2 [1,2]. Once phosphorylated, IRS-1/2 bind to and activate a series of $\mathrm{SH} 2$ motif-containing substrates, including proteins of the src family, phosphotyrosine phosphatases. such as SHPTP2, and the lipid-modifying enzyme PI 3-kinase $[1,3]$. Studies attempting to clarify early events in the insulin-signalling pathway were performed mostly in liver, muscle and adipose tissue and, although most of the metabolic actions of

*Corresponding author. Departamento de Clinica Médica, FCM UNICAMP, 13081-970, Campinas SP. Brazil. Fax: (55) (192) 393114

Abbreviations: DTT, dithiothreitol; EDTA, ethylendiaminetetracetic acid; FCS, fetal calf serum; IR, insulin receptor; IRS-1/2, insulin receptor substrate 1/2; PAGE, polyacrylamide gel electrophoresis; PI 3kinase, phosphatidylinositol 3-kinase: PMSF. phenylmethylsulfonylfluoride: SDS, sodium dodecyl sulphate; SH2 src homology ? SHPTP2, src homology protein tyrosine phosphatase 2; Tris, hydroxymethylamine methane. insulin are exerted in those tissues, it is widely accepted that insulin also possesses auto- and paracrine actions in the cells of the pancreatic islets. However, the mechanisms involved in insulin-signalling in the islets of Langerhans are not known.

Recent evidences suggest that the inhibition of tyrosine kinase activity in cultured pancreatic islets leads to a considerable increase in insulin secretion [4]. To address the issue of the involvement of tyrosine phosphorylation-mediated events in the control of islet function and in insulin-signalling in the islets of Langerhans, primary cultures of rat pancreatic islets were examined for the presence of tyrosine-phosphorylated proteins under basal and stimulated conditions.

\section{Materials and methods}

\subsection{Chemicals and antibodies}

The reagents and apparatus for SDS-PAGE and immunoblotting were from Bio-Rad (Richmond, CA). Tris, PMSF, EDTA, aprotinin and DTT were from Sigma (St Louis, MO). Sodium amobarbital and insulin were from Eli Lilly (Indiana, IN). $\left[{ }^{125}\right.$ I]Protein A was from Amersham (Buckinghamshire, UK) and Protein A Sepharose $6 \mathrm{MB}$ was from Pharmacia (Uppsala, Sweden). Nitrocellulose (BA85, 0.2 $\mathrm{mm}$ ) was from Schleicher \& Schuell (Keene, NH). Monoclonal antibodies antiphosphotyrosine and anti-p85 (PI 3-kinase) were from UBI (Lake Placid. NY). Antisera anti-IRS-1, IRS-2 and IR were raised in rabbits as previously described $[2,5]$.

\subsection{Buffers}

Buffer A contained $100 \mathrm{mM}$ Tris, $1 \%$ SDS, $50 \mathrm{mM}$ Hepes (pH 7.4), $100 \mathrm{mM}$ sodium pyrophosphate, $100 \mathrm{mM}$ sodium fluoride, $10 \mathrm{mM}$ EDTA and $10 \mathrm{mM}$ sodium vanadate. Buffer B was similar to buffer A except that $1 \%$ Triton X-100 replaced $1 \%$ SDS and $2 \mathrm{mM}$ PMSF and $0.1 \mathrm{mg} / \mathrm{ml}$ aprotinin were added. Buffer $C$ contained $100 \mathrm{mM}$ Tris, 10 $\mathrm{mM}$ sodium vanadate. $10 \mathrm{mM}$ EDTA and $1 \%$ Triton X-100.

\subsection{Animals}

Male Wistar rats were bred at the animal facilities of the State University of Campinas. The animals used in the experiments were 150-180 g and were given standard rodent chow and water ad libitum. Food was withdrawn $12-14 \mathrm{~h}$ before islet isolation.

\subsection{Islet isolation and culture}

Islets were isolated by hand-picking after collagenase digestion of the pancreas following a technique previously described [6]. In most of the experiments, the islets were preincubated overnight at $37^{\circ} \mathrm{C}$ in a humidified air incubator with $5 \% \mathrm{CO}_{2}$. The culture medium consisted RPMI containing $10 \% \mathrm{FCS}, 2 \mathrm{mM}$ glutamine, $100 \mathrm{IU} / \mathrm{ml}$ penicillin, $100 \mu \mathrm{g} / \mathrm{ml}$ streptomycin and $1.8 \mathrm{mM}$ glucose. Other culture conditions had glucose at physiologic $(5.6 \mathrm{mM})$ or high $(11 \mathrm{mM}$ or $22 \mathrm{mM})$ concentrations. When insulin was required, the hormone was added to a final concentration of $10^{-7} \mathrm{M}$.

2.5. Tissue extracts

Following the exposition to the experimental conditions, groups of 300 islets were either immediately transferred to an Eppendorf tube containing $200 \mu \mathrm{l}$ of buffer $\mathrm{A}$ and boiled for $5 \mathrm{~min}$ (when intended for 
immunoblots of total extracts) or resuspended in $1 \mathrm{ml}$ of buffer B and immediately transferred to ice (when intended for immunoprecipitations) and homogenized using a polytron PTA 20S homogenize (Brinkmann Instruments, Westbury, NY). The extracts were then centrifuged at $20,000 \times g$ to remove insoluble material. Determination of protein content in the supernatant was performed by the method of Lowry. Specimens of liver, muscle and adipose tissue used in immunoblotting in parallel to islets extracts were treated as described above for immunoblots except that the fragment of tissue was homogenized in 1.5 $\mathrm{ml}$ of buffer $\mathrm{A}$

\subsection{Immunoprecipitations}

For immunoprecipitations, samples containing $4 \mathrm{mg}$ of total protein were incubated with $15 \mu$ of antisera anti-IRS-1, IRS-2 or IR at $4^{\circ} \mathrm{C}$ overnight, followed by the addition of Protein A Sepharose 6 MB for $1 \mathrm{~h}$. The pellets were repeatedly washed in buffer $C(5 \times)$ and resuspended in $50 \mu 1$ of Laemmli sample buffer and boiled for $5 \mathrm{~min}$ prior to loading onto the gel [7].

\subsection{Protein analysis by immunoblotting}

Samples of $150 \mu \mathrm{g}$ of total protein were suspended in $50 \mu \mathrm{l}$ of Laemmli sample buffer and boiled for $5 \mathrm{~min}$ before loading onto $6 \%$ SDS-PAGE in a miniature slab gel apparatus. Electrotransfer, blotting and the procedures for analysis were as previously described [8-10]

\section{Results and discussion}

3.1. Constitutive phosphorylation of proteins in pancreatic islets cultured in low glucose concentration and regulation of tyrosine phosphorvlation by glucose and insulin

Over the past decade, there has been a dramatic increase in the understanding of early postreceptor events in insulin action

\section{$\begin{array}{lll}1.8 & 5.6 & \mathrm{mM} \text { glucose }\end{array}$}

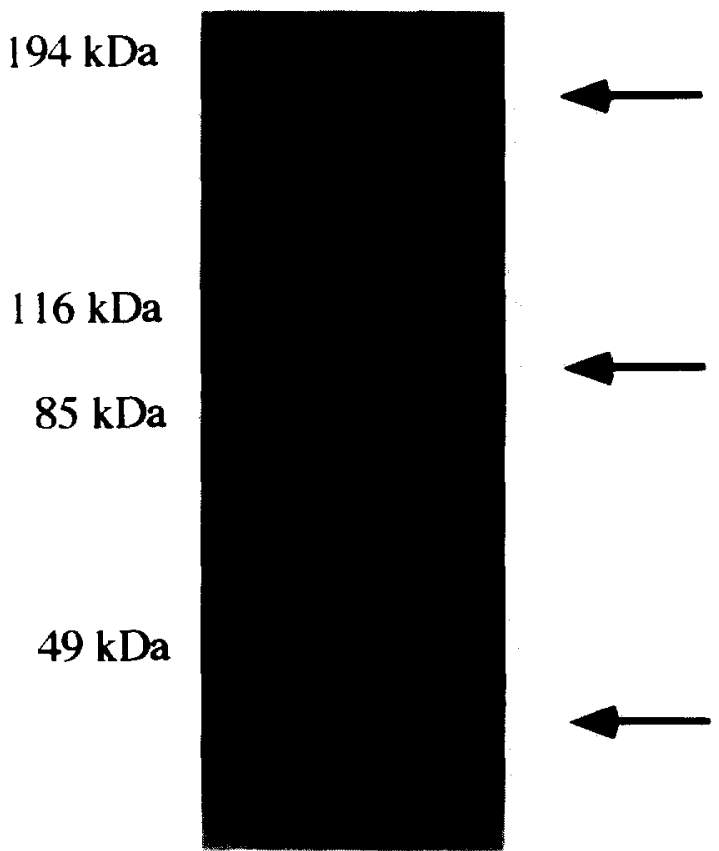

Fig. 1. Fluorography of an immunoblot of total extracts from rat pancreatic islets cultured for $12 \mathrm{~h}$ in RPMI containing 1.8 or $5.6 \mathrm{mM}$ glucose as depicted in the upper margin. At least three bands were detected upon blotting with antiphosphotyrosine antibody as indicated by the arrows in the right-hand margin. Molecular mass standards are depicted in the left-hand margin. The results are representative of four experiments run in duplicate.

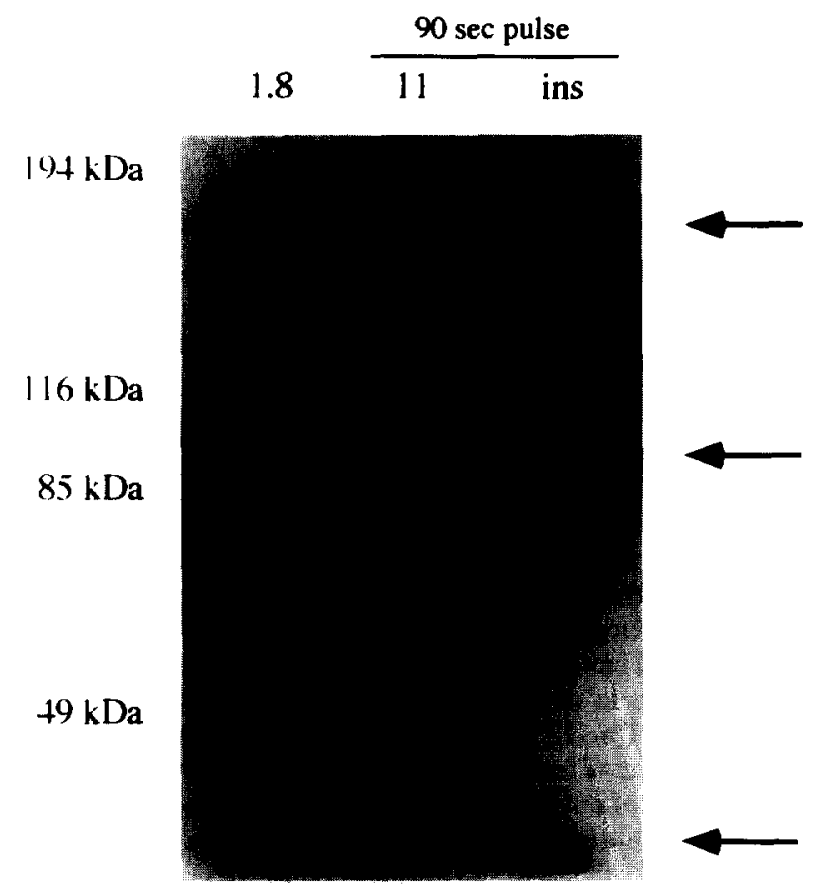

Fig. 2. Fluorography of an immunoblot of total extracts from rat pancreatic isiets cultured for $12 \mathrm{~h}$ in RPMI containing $1.8 \mathrm{mM}$ glucose and pulsed for $90 \mathrm{~s}$ with RPMI containing $11 \mathrm{mM}$ glucose or $10^{-7} \mathrm{M}$ insulin as depicted in the upper margin. Three bands detected upon blotting with antiphosphotyrosine antibody are indicated by the arrows in the right-hand margin. Molecular mass standards are depicted in the left-hand margin. The results are representative of three experiments run in duplicate.

$[1,3]$. After insulin binds to the $\alpha$ subunit of its receptor, there is an activation of the kinase in the $\beta$ subunit, thus, enhancing the tyrosine kinase activity of the receptor towards intracellular protein substrates $[1,3]$. In most cells, this event leads to the subsequent tyrosil phosphorylation of two cytoplasm proteins with an apparent molecular mass of $165-185 \mathrm{kDa}$, namely IRS- 1 and IRS-2. Phosphorylated IRS-1/2 associate and activate the lipid metabolizing enzyme PI 3-kinase [1-3]. Thus, IR, IRS-1, IRS-2 and PI 3-kinase represent some of the earliest steps in insulin action. These initial steps have been well-characterized in classic insulin target tissues, i.e. liver, muscle and fat [11-13]. However, as no information was available regarding a possible involvement of this pathway in auto- and paracrinesignalling in pancreatic islets, we initially used immunoblotting to search for tyrosine-phosphorylated proteins in isolated rat pancreatic islets.

Groups of 300 islets each were cultured for $12 \mathrm{~h}$ in RPMI containing 1.8 or $5.6 \mathrm{mM}$ glucose. Total islet extracts were analysed by immunoblotting using an antiphosphotyrosine antibody and showed that at least three distinct bands $(25 \mathrm{kDa}$, $95 \mathrm{kDa}$ and $165-185 \mathrm{kDa}$ ) were phosphorylated. Densitometric scanning of the bands revealed no differences in phosphorylation levels between proteins from islets cultured in media containing glucose concentrations bellow the threshold for the stimulation of insulin secretion $(1.8 \mathrm{mM})$ and those cultured at a physiologic glucose level $(5.6 \mathrm{mM})$ (Fig. 1) $(n=4)$. Furthermore, when islets cultured for $12 \mathrm{~h}$ in media containing $1.8 \mathrm{mM}$ glucose were pulsed for $90 \mathrm{~s}$ with media containing $11 \mathrm{mM}$ 

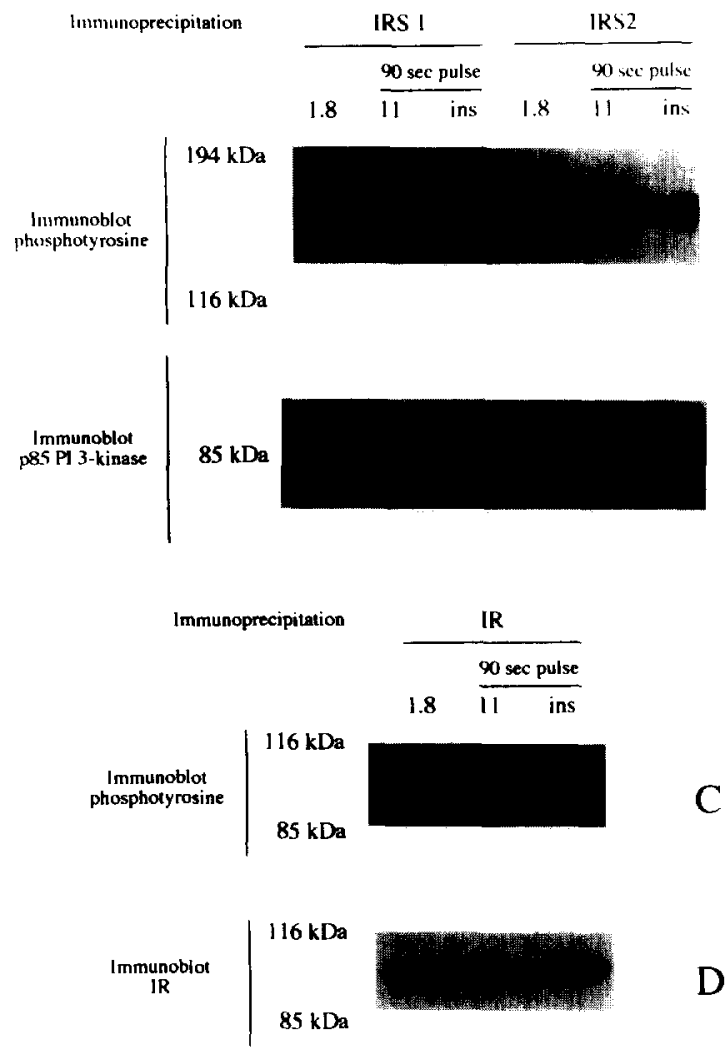

Fig. 3. Fluorography of immunoblots of IRS-1. IRS-2 or IR immunoprecipitates from rat pancreatic islets cultured for $12 \mathrm{~h}$ in RPMl containing $1.8 \mathrm{mM}$ glucose and pulsed for $90 \mathrm{~s}$ with RPMI containing $11 \mathrm{mM}$ glucose or $10^{-7} \mathrm{M}$ insulin as depicted in the upper margins of $A$ and $C$. In A, the upper part of the nitrocellulose membrane of IRS-1 and IRS-2 immunoprecipitates was blotted with antiphosphotyrosine antibody while, in B, the lower part of the same membrane was blotted with anti-p85 PI 3-kinase antibody. In C. the nitrocellulose membrane of IR immunoprecipitates was blotted with antiphosphotyrosine antibody and in $\mathrm{D}$ the same nitrocellulose membrane was reblotted, after stripping, with anti-IR antibody. Molecular mass standards are depicted in the left-hand margin. The results are representative of three experiments run in duplicate.

glucose or $10^{-7} \mathrm{M}$ insulin, the tyrosine phosphorylation levels of all three bands were increased (Fig. 2) $(n=3)$.

\subsection{Phosphorylation of IRS-1, IRS-2 and the $\beta$ subunit of the} $I R$ and association of $I R S 1 / 2$ with the $p 85$ subunit of $P I$ 3-kinase are increased after a pulse of high glucose or exogenous insulin

As the apparent molecular mass of two of the bands were $165-185 \mathrm{kDa}$ and $95 \mathrm{kDa}$, it was suspected that they could correspond to IRS-1, IRS- 2 and the $\beta$ subunit of the IR, respectively. This hypothesis was tested by performing immunoprecipitations with anti-IRS-1, -IRS-2 or -IR antisera. Groups of 300 islets cultured for $12 \mathrm{~h}$ in media containing $1.8 \mathrm{mM}$ glucose were pulsed for $90 \mathrm{~s}$ with media containing $11 \mathrm{mM}$ glucose or insulin at a final concentration of $10^{-7} \mathrm{M}$. Nitrocellulose membranes containing the immunoprecipitates were initially blotted with antiphosphotyrosine antibody. IRS-1. IRS-2 and IR were phosphorylated at the basal condition and underwent an increase in the tyrosine phosphorylation level after both $11 \mathrm{mM}$ glucose or $10^{-7} \mathrm{M}$ insulin pulse. The increases in the phosphorylation levels were 2- and 3-fold for IRS-1 after $11 \mathrm{mM}$ glucose and $10^{-7} \mathrm{M}$ insulin, respectively, 2- and 2.5-fold for IRS-2 after $11 \mathrm{mM}$ glucose and $10^{-7} \mathrm{M}$ insulin, respectively, and 2- and 2.5-fold for IR after $11 \mathrm{mM}$ glucose and $10^{-7} \mathrm{M}$ insulin, respectively (Fig. 3a,c) (data representative of $n=3$ ). The lower part of the membranes from the IRS-1 and IRS-2 immunoprecipitates were blotted with the anti-p85 antibody and the associations of IRS-1 and IRS-2 with the regulatory subunit of PI 3-kinase were detected. The increases in IRS-1-p85 association after $11 \mathrm{mM}$ glucose and $10^{-7} \mathrm{M}$ insulin pulse were 1.5 - and 2.5-fold, respectively. The increases in IRS-2-p85 association after $11 \mathrm{mM}$ glucose and $10^{-7} \mathrm{M}$ insulin were 1.5- and 2.3-fold, respectively (Fig. $3 \mathrm{~b}$ ) (data representative of $n=3$ ). The nitrocellulose membranes of the IR immunoprecipitates were reblotted using anti-IR antiserum and the amount of IR was similar in all three conditions (Fig. $3 \mathrm{~d})(n=3)$. These results provide evidence that the tyrosine-phosphorylated band at 165-185 $\mathrm{kDa}$ corresponds to the primary substrates of the IR, IRS-1 and IRS-2 and that the degree of tyrosine phosphorylation of the substrates is responsive to short exposition to insulin or high glucose. After longer expositions ( $60 \mathrm{~min}$ or $12 \mathrm{~h}$ ) to the same concentrations of insulin or glucose, the level of tyrosine phosphorylation of all bands return to nearly basal (data not shown). Shorter exposition to $11 \mathrm{mM}$ glucose does not induce an increase in the phosphorylation of the bands while expositions as short as $30 \mathrm{~s}$ to insulin at $10^{-7} \mathrm{M}$ still produce an increase in the tyrosine phosphorylation of all three bands (Fig. 4). Thus, two possible explanations are proposed: (1) Insulin
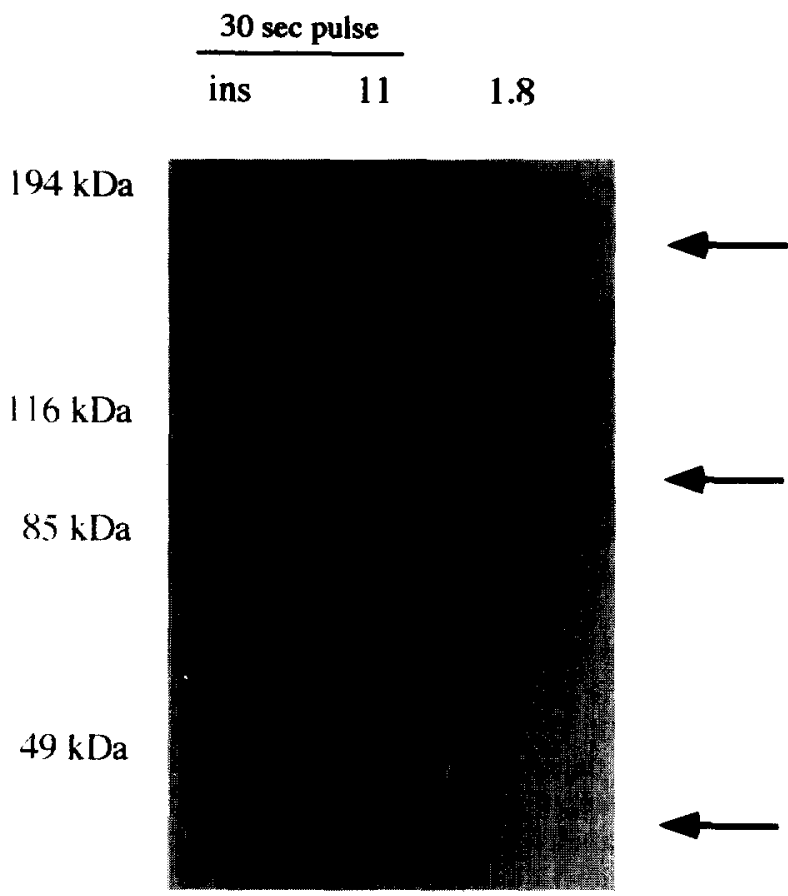

Fig. 4. Fluorography of immunoblots of IRS-1 immunoprecipitates from rat pancreatic islets cultured for $12 \mathrm{~h}$ in RPMI containing $1.8 \mathrm{mM}$ glucose and pulsed for $30 \mathrm{~s}$ with RPMI containing $11 \mathrm{mM}$ glucose or $10^{-7} \mathrm{M}$ insulin as depicted in the upper margin. Three bands detected upon blotting with antiphosphotyrosine antibody are indicated by the arrows in the right-hand margin. Molecular mass standards are depicted in the left-hand margin. The results are representative of two experiments run in duplicate. 
A

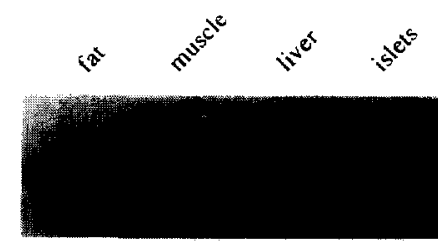

IRS 1

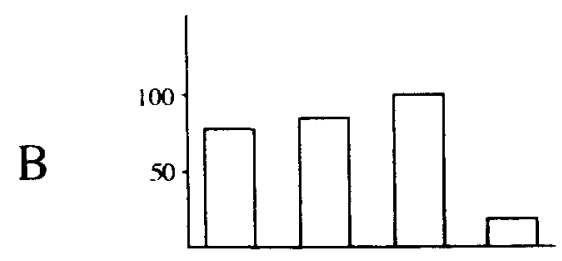

IRS 1

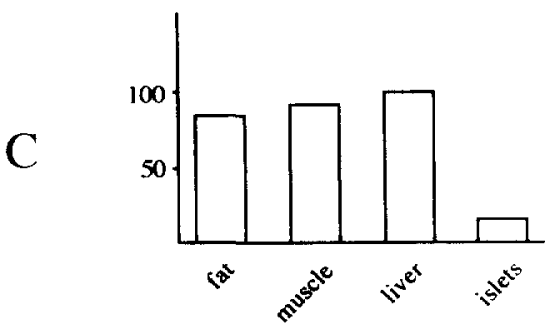

IR

Fig. 5. (A) Fluorography of an immunoblot of total extracts from rat adipose tissue, muscle, liver and pancreatic islets as depicted in the upper margin. $200 \mu \mathrm{g}$ of total protein was run in each lane and after transfer, the nitrocellulose membranes were blotted with anti-IRS-1 antibody. The arrow in the right-hand margin indicates the position of IRS-1. The results are representative of two experiments run in duplicate. (B,C) Graphs depicting the relative amounts of IRS-l (B) and IR (C) expressed in adipose tissue, muscle, liver and pancreatic islets of the rat. The results are representative of two experiments run in duplicate.

treatment leads to IRS phosphorylation and subsequent PI 3-kinase association while glucose treatment leads to the phosphorylation of IRS at a different site, which does not lead to PI 3-kinase association. (2) The effect upon tyrosine phosphorylation after a pulse of high glucose is in fact exerted by an autocrine loop of the secreted insulin.

The identity of the third band $(25 \mathrm{kDa})$ was not determined but, as its degree of phosphorylation underwent variations in accordance with those of the 165-185 kDa and $95 \mathrm{kDa}$ bands, it is suspected that it corresponds to another protein involved in the intracellular insulin-signalling pathway, downstream to the IR.

Sorensen and coworkers [4], using inhibitors of tyrosine kinase, found a 5- to 10-fold increase in insulin secretion in isolated neonatal rat pancreatic islets. Moreover, during the revision of this paper Rothemberg and coworkers [14] showed that an insulin secreting cell line express both IRS-1 and IR and that they are rapidly phosphorylated after insulin and IGF 1 treatment. Finally, Kisanuki and coworkers [15] detected the presence of IR in clonal pancreatic $\alpha$ cells. Recent experiments have shown that in tissues that are traditional targets for insulin action, PI 3-kinase activation leads to the migration of glucose transporters from an intracellular pool to the cell surface. thus. regulating the uptake of glucose [16]. PI 3-kinase is also known to associate with dynamin and has been implicated in the regulation of secretory vesicle trafficking [17]. Apparently, via an autocrine loop, insulin exerts an inhibitory action upon the secretory activity of the $\beta$ cell. Although the intracellular mechanism responsible for this regulation is currently unknown, the PI 3-kinase pathway might be involved. Thus, it is possible that glucose-induced insulin secretion by the pancreatic $\beta$ cell could, via an autocrine activation of the IR-signalling pathway, modulate negatively the $\beta$ cell's own function. Experiments with wortmannin, an inhibitor of PI 3-kinase [18], could be useful as a tool for answering this question.

\subsection{Relative amounts of IRS-I and IR in pancreatic islets in comparison to tissues that are traditional targets for insulin} action

$200 \mu \mathrm{g}$ of total protein from freshly prepared homogenates of liver, fat and muscle were separated by SDS-PAGE in parallel to the same amount of proteins from rat pancreatic islets cultured for $12 \mathrm{~h}$ in RPMI containing $1.8 \mathrm{mM}$ glucose. Nitrocellulose membranes from the electrotransfers were blotted with antisera anti-IRS-1 and -IR. Quantitation by densitometric scanning of the specific bands revealed that the IRS-1 was present in liver, muscle, fat and islets in the following proportions based on arbitrary densitometric units: 100, 85, 78 and 18 . For the IR, the relation was $100,92,85$ and 16 , respectively, for liver, muscle, fat and pancreatic islets $(n=2)$ (Fig. 5).

In summary, isolated rat pancreatic islets possess proteins that are phosphorylated at tyrosine residues. The level of phosphorylation is regulated by glucose and insulin although the effects of glucose occurs possibly through its insulin secretory activity. Three of these proteins were identified as components of the insulin-signalling pathway and may be involved in autoand paracrine regulation in the islets of Langerhans.

Acknowledgements: We thank Drs. C.R. Kahn, M.F. White and X.J. Sun (Joslin Diabetes Center, Harvard Medical School at Boston, Boston, MA) for the kind donation of antisera anti-IR, -IRS-1 and -IRS-2 and to Mr. L. Janeri and Mrs. C. da Silva for technical assistance. This work was supported by grants from FAPESP and CNPq.

\section{References}

[1] Kahn, C.R. (1994) Diabetes 43, 1066-1084.

[2] Sun, X.J., Wang, L.M., Zhang, Y., Yenush, L., Myers, Jr., M.G., Glasheen, E., Lane, W., Pierce, J. and White, M.F. (1995) Diabetes 44 (supp. 1), 182.

[3] White, M.F. and Kahn, C.R. (1994) J. Biol. Chem. 269, 1-4.

[4] Sorensen, R.L., Brelje, T.C. and Roth, C. (1994) Endocrinology 134, 1975-1978.

[5] Rothemberg, P.L., Lane, W.S., Karasik, A., Baker, J., White, M.F. and Kahn, C.R. (1991) J. Biol. Chem. 266, 8302-8311.

[6] Boschero, A.C., Szpak-Glasman, M., Carneiro, E.M., Bordin, S., Paul, I., Rojas, E. and Atwater, I. (1995) Am. J. Physiol. 268, E336-E342.

[7] Laemmli, U.K. (1970) Nature (London) 277, 680-685.

[8] Towbin, H.J., Staehlin, J. and Gordon, J. (1979) Proc. Natl. Acad. Sci. USA 76, 4350-4354.

[9] Saad, M.J.A., Folli, F., Kahn, J.A. and Kahn, C.R. (1993) J. Clin. Invest. 92, 2065-2072.

[10] Velloso, L.A., Kämpe, O., Hallberg, A., Christmanson, L., Betsholtz, C. and Karlsson, A. (1993) J. Clin. Invest. 91, 20842090

[11] Saad. M.J.A., Araki, E., Miralpeix, M., Rothemberg, P.L., White, M.F. and Kahn, C.R. (1992) J. Clin. Invest. 90, 1839-1849.

[12] Folli. F., Saad, M.J.A., Backer, J.M. and Kahn, C.R. (1993) J. Clin. Invest. 92, 1787-1794.

[13] Saad, M.J.A., Folli, F., Araki, E., Hashimoto, N., Csermley, P. and Kahn, C.R. (1994) Mol. Endocrinol. 8, 545-557. 
[14] Rothemberg, P.L., Willison L.D., Simon, J. and Wolf, B.A. (1995) Diabetes 44, 802-809.

[15] Kisanuki, K., Kishikawa, H., Araki, E., Shirotani. T., Uehara, M. Isami, S., Ura, S., Jinnouchi, H., Miyamura. N. and Shichiri, M. (1995) Diabetologia 38, 422-429.

[16] Backer, J.M., Myers, Jr., M.G., Shoelson, S.E., Chin, D.J., Sun, X.J., Miralpeix, M., Hu, P., Margolis, B., Skolnik, E.Y., Schlessinger, J. and White. M.F. (1992) EMBO J. 11. 3469-3479.
[17] Ando, A.. Yonezawa, K., Gout, I., Nakata, T., Ueda, H., Hara, K., Kitamura, Y., Noda, Y., Takenawa, T., Hirokawa, N., Waterfield, M. and Kasuga, M. (1994) EMBO J. 13, 3033-3038.

[18] Yano, H.. Nakanishi, S., Kimura, K., Hanai, N., Saitoh, Y., Fukui, Y., Nonomura, Y. and Matsuda, Y. (1993) J. Biol. Chem. $268,25846-25856$. 